УДК 547.972

\title{
РАЗРАБОТКА СПОСОБА ПОЛУЧЕНИЯ СТАНДАРТНОГО ОБРАЗЦА 1-ГИДРОКСИ-2,3,5-ТРИМЕТОКСИКСАНТОНА
}

\author{
() Т.М. Шиимарева", Л.М. Танхаева, Д.Н. Оленников
}

Институт общей и экспериментальной биологии СО РAH, ул. Сахьяновой, 6,
Улан-Удэ, 670047 (Россия), e-mail: shishmarevatm@rambler.ru

Разработан способ получения стандартного образца 1-гидрокси-2,3,5-триметоксиксантона из надземной части Halenia corniculata (L.) Cornaz. (Gentianaceae), используемый в качестве стандартного образца для количественной оценки суммарного содержания $\gamma$-пироновых соединений в данном виде растительного сырья. Предложенный способ получения отличается от способов-аналогов большим выходом целевого продукта и упрощенной технологической схемой.

Ключевые слова: ксантоны, Halenia corniculata, Gentianaceae, стандартный образец, 1-гидрокси-2,3,5-триметоксиксантон.

\section{Введение}

Галения рогатая (Halenia corniculata (L.) Cornaz., Gentianaceae) - лекарственное растение, обладающее широким спектром биологической активности как желчегонное, седативное, диуретическое, жаропонижающее, возбуждающее аппетит средство $[1,2]$. Надземная часть $H$. corniculata (gser tig) применяется в тибетской медицине при заболеваниях гепато-билиарной системы [3], а также при неврастении, энтероколитах, желтухе, гастрите, воспалительных заболеваниях кишечника, холецистите, болезнях печени и желчевыводящих путей [4-7].

Химические исследования $H$. corniculata выявили присутствие в надземной части ксантонов [8-11], флавоноидов [8, 10, 12], секоиридоидов [10, 13], алкалоидов, эфирного масла и дубильных веществ [14]. Доминирующими компонентами в составе $\gamma$-пироновых соединений $H$. corniculata являются 1-гидрокси2,3,4,5-тетраметоксиксантон (1), 1-гидрокси-2,3,5-триметоксиксантон (2) и лютеолин-7-глюкозид (3) [15]. Для 1 и 3 ранее были разработаны способы получения [16, 17].

В литературе описаны следующие способы получения 2. Из корней Frasera albicaulis Dougl. ex Griesb. (Gentianaceae): экстракция растительного сырья метанолом, жидкофазная экстракция 20\% раствором дихлорметана в пентане, концентрирование полученного извлечения, КХ на $\mathrm{SiO}_{2}$ (гексан - этилацет $2: 1$ ), перекристаллизация из смеси растворителей дихлорметан/гексан. Выход 0,04\% от массы возд.-сух. сырья [18]. Из корней и надземной части Halenia asclepidea (HBK) Don (Gentianaceae): экстракция растительного сырья гек-

Шишмарева Татьяна Михайловна - младший научный сотрудник лаборатории медико-биологических исследований, кандидат фармацевтических наук, тел.: (3012) 43-34-63, e-mail: shishmarevatm@rambler.ru Танхаева Лариса Максимовна - старший научный сотрудник лаборатории медико-биологических исследований, кандидат фармацевтических наук, тел.: (3012) 43-34-63, e-mail: oldaniil@ rambler.ru Оленников Даниил Николаевич - старший научный сотрудник лаборатории медико-биологических исследований, кандидат фармацевтических наук, тел.: (3012) 43-34-63, e-mail: oldaniil@ rambler.ru саном, концентрирование полученного извлечения, растворение в дихлорметане, фильтрование, экстрагирование водно-метанольным раствором $\mathrm{KOH}$, разбавление водой, подкисление и экстракция дихлорметаном, препаративная ТCX на $\mathrm{SiO}_{2}$ (петролейный эфир этилацетат 8:1), перекристаллизация из метанола. Выход 0,06 от массы возд.-сух. сырья [19]. Из корней и надземной части Halenia elliptica D. Don (Gentianaceae): экстракция растительного сырья этанолом, концентрирование извлечения, $\mathrm{KX}$ на $\mathrm{SiO}_{2}$ (гексан - ацетон $19: 1 \rightarrow 18: 2)$, перекристаллизация из метанола.

\footnotetext{
* Автор, с которым следует вести переписку.
} 
Выход - 0,08\% от массы возд.-сух. сырья [20]. Из корней и надземной части Halenia campanulata (Gentianaceae): экстракция растительного сырья дихлорметаном и метанолом, концентрирование извлечения, КХ на $\mathrm{SiO}_{2}$ (петролейный эфир - этилацетат $3: 1$ ), перекристаллизация из метанола. Выход $0,11 \%$ от массы возд.сух. сырья [21]. Из корней Frasera caroliniensis Walt. (Gentianaceae): экстракция растительного сырья ацетоном, жидко-фазная экстракция смесью растворителей дихлорметаном - пентаном, концентрирование извлечения, кристаллизация из метанола, $\mathrm{KX}$ на $\mathrm{SiO}_{2}$ (гексан - этилацетат $3: 1$ ), перекристаллизация из смеси растворителей дихлорметан/гексан и метанола. Выход - $0,11 \%$ от массы возд.-сух. сырья [22].

Недостатками указанных способов являются низкий выход целевого продукта, длительность и трудоемкость технологического процесса.

Цель настоящего исследования - разработка способа получения стандартного образца 1-гидрокси2,3,5-триметоксиксантона (2) из надземной части H. corniculata.

\section{Экспериментальная часть}

Растительное сырье. Надземная часть $H$. corniculata была собрана в фазу цветения в окр. с. Мантуриха (Кабанский район, республика Бурятия, 20.VIII.2007). Видовая принадлежность определена канд. фарм. наук Г.В. Чехировой (ИОЭБ СО РАН). Образцы H. corniculata хранятся в гербарии ИОЭБ СО РАН (№ $\mathrm{Gn} / \mathrm{h}-02 / 22-11 / 2081$ ).

Общие экспериментальные условия. Температуру плавления определяли на микронагревательном столике (Kofler). ИК-спектры регистрировали на спектрометре Vector 22 (Bruker) в таблетке с КВr. УФспектры поглощения записывали на спектрофотометре 8453 UV-Vis (Hewlett-Packard) в 96\% этаноле. Для определения молекулярных масс и элементного состава использовали MC-спектрометр высокого разрешения MAT 8200 (Finnigan). Спектры ЯМР регистировали на спектрометре AC 200 (Bruker). Мультиплетность сигналов в спектрах ЯМР ${ }^{13} \mathrm{C}$ определяли по стандартным методикам снятия спектров в режиме $J$-модуляции (J-MOD). ВЭЖХ проводили с использованием микроколоночного жидкостного хроматографа Милихром А-02 (Эконова); подвижная фаза - 0.1\% ТФУ в MeOH; колонка ProntoSIL-120-5-C-18 AQ (2×75 мм, 5 мкм), $35^{\circ} \mathrm{C}, v 150$ мкл/мин; УФ-детектор при 244, 260, 320 нм.

Хроматографическое разделение ксантонов проводили на колонках с силикагелем (L 100/400 и L 100/250), используя в качестве элюентов хлороформ (I) и системы растворителей (CP): гексан - этилацетат $7: 3$ (II), гексан - этилацетат $8: 2$ (III) и гексан - этилацетат $6: 4$ (IV). Контроль за разделением веществ осуществляли с помощью TCX на пластинах Silufol в CP II; детектор - $5 \% \mathrm{AlCl}_{3}$ в этаноле.

Meтод 1. 100 г воздушно-сухого, измельченного сырья H. corniculata экстрагировали 95\% этанолом (3×1000 мл), спиртовое извлечение фильтровали и концентрировали до объема 200 мл. Водный остаток переносили в делительную воронку, приливали 100 мл воды очищенной, после чего ксантоновые агликоны извлекали хлороформом (3×1000 мл). Объединенное хлороформное извлечение концентрировали до объема 100 мл, смешивали с силикагелем (L 100/250 мкм, 40 г), высушивали и хроматографировали на колонке с силикагелем (L 100/250 мкм, 100 г; $4 \times 50$ cм), используя в качестве элюента I. Объем фракций - 50 мл. Фракции 16-20, содержащие 2, объединяли, концентрировали досуха и дважды перекристаллизовывали из этанола. Получено 0,02 г 2 (0,02\% от массы возд.-сух. сырья).

Метод 2. Хлороформную фракцию получали, как описано в методе 1 , и далее наносили на колонку с силикагелем (L 100/250, 100 г; 4×50 см), которую элюировали CP II. Объем фракций - 50 мл. Фракции 14-17, содержащие 2, объединяли, концентрировали досуха и дважды перекристаллизовывали из этанола. Получено 0.15 г 2 (0.15\% от массы возд.-сух. сырья).

Meтоды 3 u 4. Аналогично методу 2 с использованием в качестве элюента III и IV соответственно получено 20,01 г (0,01\% от массы возд.-сух. сырья) и 0,10 г (0,10\% от массы возд.-сух. сырья) соответственно для методов 3 и 4.

Meтод 5. 100 г воздушно-сухого, измельченного сырья H. corniculata экстрагировали 2\% раствором $\mathrm{HCl}$ в 95\% этаноле на кипящей водяной бане в течение 3 ч (3×1000 мл). Объединенные спиртовые извлечения отфильтровывали и концентрировали до объема 200 мл. Полученное извлечение переносили в делительную воронку, приливали 100 мл воды очищенной, после чего ксантоновые агликоны извлекали хлороформом ( $3 \times 500$ мл). Объединенное хлороформное извлечение промывали водой очищенной до нейтральной реакции и концентрировали до объема 100 мл. Последующие операции проводились аналогично методу 1. Получено 0,01 г 2 (0,01\% от массы возд.-сух. сырья). 


\section{Обсуждение результатов}

В ходе работы нами были исследованы пять методов получения 2. Установлено, что выход 2 составил $0,01-0,15 \%$. Учитывая тот факт, что метод 5 включал в себя одновременный гидролиз $2 \% \mathrm{HCl}$, целевой продукт был загрязнен олеаноловой кислотой, которая мешает разделению и получению соединения в индивидуальном состоянии. В результате проведенной работы установлено, что наибольший выход 2 (0,15\% от массы возд.-сух. сырья) достигается с применением метода 2.

С применением метода 2 получен ряд серий 2. Идентификацию 1-гидрокси-2,3,5-триметоксиксантона проводили с использованием ТСХ,

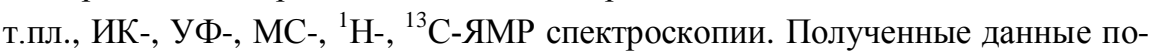
казывают, что физико-химические показатели целевого продукта аналогичны таковым химически чистого 2.

1-гидрокси-2,3,5-триметоксиксантон (2). $\mathrm{R}_{f}^{\mathrm{TCX}} 0,20$ (CP I), $\mathrm{R}_{\mathrm{f}} 0,57$ (CP II). Т.пл. 189-190 ${ }^{\circ} \mathrm{C}$. ИК-спектр ( $\left(\mathrm{cm}^{-1}\right):$ 742, 792, 840, 959, 993, 1088, 1497 , 1585, $1611(\mathrm{C}=\mathrm{C}), 1658(\mathrm{C}=\mathrm{O})$. УФ-спектр (МеОН, $\lambda_{\max }$, нм): 220, 245, 253 пл., 273 пл., 306, 360, Спектр ЯМР ${ }^{1} \mathrm{H}\left(200,13\right.$ МГц, $\mathrm{CDCl}_{3}, \delta$, м.д.): 3,90 (3Н, с, $\left.\mathrm{OCH}_{3}\right), 3,92\left(3 \mathrm{H}, \mathrm{c}, \mathrm{OCH}_{3}\right), 4,00\left(3 \mathrm{H}, \mathrm{c}, \mathrm{OCH}_{3}\right), 6,58(1 \mathrm{H}, \mathrm{c}, \mathrm{H}-4), 7,20(1 \mathrm{H}$, дд, J 7,5, 1,8, H-6), 7,27 (1H, т, J 7,5, H-7), 7,78 (1H, дд, J 7,5, 1,8, H-8), 12,73 (1H, c, $\mathrm{OH})$. Спектр ЯМР ${ }^{13} \mathrm{C}\left(50,32 \mathrm{MГц,} \mathrm{CDCl}_{3}\right.$, $\delta$, м.д.): 56,27 $\left(\mathrm{CH}_{3}\right), 56,32\left(\mathrm{CH}_{3}\right)$, 60,74 ( $\left.\mathrm{CH}_{3}\right), 90,82$ (C-4), 104,18 (C-8a), 115,42 (C-6), 116,55 (C-7), 121,06 (C-5a), 123,45 (C-8), 131,86 (C-4a), 146,18 (C-1a), 148, 17 (C-5), 153,04 (C-3), 154,00 (C-2), 159,90 (C-1), 180,97 (C-9). MC ( $\mathrm{m} / \mathrm{z}, \%): 302$ (91,22), 287 (100), 273 (13,75), 259 (63,72), 244 (10,52), 216 (16,86), $122(11,71) . \mathrm{C}_{16} \mathrm{H}_{14} \mathrm{O}_{6}$, Расч. 302,07903, Эксп. 302,07884, $\mathrm{E}_{\text {1\%м }}^{1 \%}$ (ЕtOH, 253 нм): 854.

Согласно данным ВЭЖХ содержание основного вещества 2 в выде-

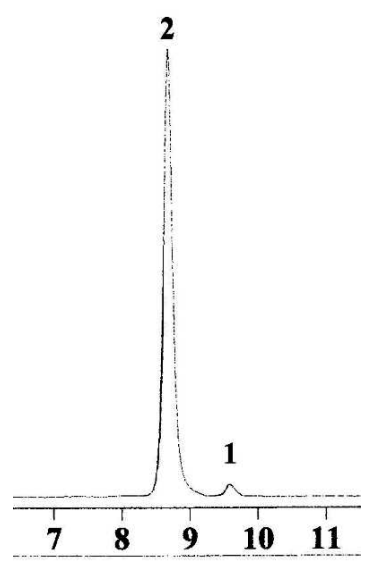
ленном продукте составляет 96-97\% (рис.). Примесь с $\mathrm{t}_{R}$ 9,81 мин идентифицирована как 1-гидрокси2,3,4,5-тетраметоксиксантон (1), содержание которого не превышает $3 \%$.

\section{Bblвodbl}

Разработан способ получения стандартного образца 1-гидрокси-2,3,5-триметоксиксантона, заключающийся в том, что растительное сырье (надземная часть Halenia corniculata (L.), Cornaz, Gentianaceae) трижды экстрагируют 96\% этанолом, с последующим отгоном этанола и жидкофазной экстракцией водного остатка хлороформом трижды, колоночной хроматографией на силикагеле с использованием в качестве элюента смеси растворителей гексан - этилацетат $7: 3$, концентрированием и двойной перекристаллизацией из этанола $(0,15 \%$ от массы возд.-сух. сырья).

\section{Список литературы}

1. Телятьев В.В. Полезные растения Центральной Сибири. Иркутск, 1985. 383 с.

2. Шретер А.И. Лекарственная флора советского Дальнего Востока. М., 1975. 328 с.

3. Гаммерман А.Ф., Семичов Б.В. Словарь тибетско-латино-русских названий лекарственного растительного сырья, применяемого в тибетской медицине. Улан-Удэ, 1963. 180 с.

4. Баторова С.М. Желчегонная активность отваров из некоторых растений Забайкалья // Растительные ресурсы. 1983. T. 19. C. 380-383.

5. Blinova K.F., Kalyupanova A.I. Xanthone glycosides of Iris ensata // Chemistry of Natural Compounds. 1974. Vol. 10, N4. P. 551.

6. Варлаков М.Н. Избранные труды. М., 1963. 172 с.

7. Самбуева 3.Г. Новые виды растительного сырья с желчегонной активностью из флоры Сибири // Лекарственные растения в традиционной и народной медицине. Улан-Удэ, 1987. С. 127-129.

8. Tankhaeva L.M., Nikolaeva G.G., Glyzin V.I., Pinchuk I.N. $\gamma$-Pyrone derivatives from Halenia corniculata // Chemistry of Natural Compounds. 1984. Vol. 20, N6. P. 747.

9. Танхаева Л.М., Пуреб О., Комиссаренко Н.Ф., Николаева Г.Г., Одонтуяа Г. Ксантоны Halenia corniculata (L.) Cornaz из Монголии // Растительные ресурсы. 1993. Т. 31. С. 57-61.

10. Rodriguez S., Wolfender J.-L., Odontuya G., Purev O., Hostettmann K., Xanthones, secoiridoids and flavonoids from Halenia corniculata // Phytochemistry. 1995. Vol. 40. Pp. 1265-1272. 
11. Odontuya G., Kojima K., Rodriguez S., Purev O., Ogihara Y., Hostettmann K. Xanthones from Halenia corniculata // Chemical \& Pharmaceutical Bulletin. 1998. Vol. 46. Pp. 1827-1828.

12. Пуреб О., Одонтуяа Г., Хишгээ Д., Оюун Х., Танхаева Л.М., Николаева Г.Г., Комиссаренко Н.Ф. Флавоноиды Halenia corniculata (L.) Cornaz и Lomatogonium rotatum (L.) Fries ex Fern. (Монголия) // Растительные ресурсы. 1994. T. 30. C. $148-151$.

13. Rodriguez S., Wolfender J.-L., Hostettmann K., Odontuya G., Purev O. Corniculoside, a new biosidic ester secoiridoid from Halenia corniculata // Helvetica Chimica Acta. 1996. Vol. 79. P. 363-370.

14. Карпович В.Н. Фитохимическое исследование забайкальских видов Горечавковых // Вопросы фармакогнозии. 1960. T. 12. C. 201-208.

15. Mikhailova T.M., Olennikov D.N., Tankhaeva L.M., Nikolaeva G.G. Xanthones from Halenia corniculata. 2. Quantitative determination of total $\gamma$-pyrone content in the aerial part // Chemistry of Natural Compounds. 2005. Vol. 41, N3. Pp. 303-305.

16. Mikhailova T.M., Tankhaeva L.M., Shul'ts E.E., Tolstikov G.A. Xanthones from Halenia corniculata. 3. Preparation of standard 1-hydroxy-2,3,4,5-tetramethoxyxanthone // Chemistry of Natural Compounds. 2005. Vol. 41, N5. Pp. 513-515.

17. Михайлова Т.М., Шульц Э.Э., Танхаева Л.М., Николаева Г.Г., Бодоев Н.В., Толстиков Г.А. Биологическая активность фенольных соединений, выделенных из галении рогатой (Halenia corniculata (L.) Cornaz) // Химия в интересах устойчивого развития. 2005. №3. С. 411-415.

18. Stout G.H., Christensen E.N., Balkenhol W.J., Stevens K.L. Xanthones of the Gentianaceae - II. Frasera albicaulis Dougl. ex Griesb. // Tetrahedron. 1969. Vol. 25. Pp. 1961-1973.

19. Stout G.H., Fries J.L. The xanthones of a Halenia species // Phytochemistry. 1970. Vol. 9. Pp. 235-236.

20. Dhasmana H., Garg H.S. Two xanthone glucosides from Halenia elliptica // Phytochemistry. 1989. Vol. 28. Pp. 2819-2821.

21. Recio-Iglesias M.-C., Marston A., Hostettmann K. Xanthones and secoiridoids glucoside of Halenia campanulata // Phytochemistry. 1992. Vol. 31. Pp. 1387-1389.

22. Stout G.H., Balkenhol W.J. Xanthones of the Gentianaceae - I. Frasera caroliniensis Walt. // Tetrahedron. 1969. Vol. 25. Pp. 1947-1960.

Поступило в редакцию 19 декабря 2011 2.

Shishmareva T.M.*, Tankhaeva L.M., Olennikov D.N. PREPARATION OF STANDARD 1-HYDROXY-2,3,5TRIMETHOXYXANTHONE

Institute of General and Experimental Biology SD RAS, Sakh'yanovoy st., 6, Ulan-Ude, 670047 (Russia),

e-mail:shishmarevatm@rambler.ru

A method of standard 1-hydroxy-2,3,5-trimethoxyxanthone isolation was developed. 1-Hydroxy-2,3,5-trimethoxyxanthone was isolated from the aerial part of Halenia corniculata L. Cornaz and used as a standard for quantitative determination of $\gamma$-pyrones total content in this plant species. The proposed method was characterized by a high yield of the end product and a simplified process scheme.

Keywords: xanthones, Halenia corniculata, Gentianaceae, standard sample, 1-hydroxy-2,3,5-trimethoxyxanthone.

\footnotetext{
* Corresponding author.
} 


\section{References}

1. Telyat'ev V.V. Poleznye rasteniya Tsentral'noy Sibiri. [Useful plants of Central Siberia]. Irkutsk, 1985. 383 p. (in Russ.).

2. Shreter A.I. Lekarstvennaya flora sovetskogo Dal'nego Vostoka. [Medicinal Flora of the Soviet Far East]. Moscow, 1975. 328 p. (in Russ.).

3. Gammerman A.F., Semichov B.V. Slovar' tibetsko-latino-russkikh nazvaniy lekarstvennogo rastitel'nogo syr'ya, primenyaemogo $v$ tibetskoi meditsine. [Tibetian-Latin-Russian Names of Medicinal Plants Used in Tibetian Medicine]. Ulan-Ude, 1963. 180 p. (in Russ.).

4. Batorova S.M. Rastitel'nye Resursy, 1983, vol. 19, pp. 380-383. (in Russ.).

5. Blinova K.F., Kalyupanova A.I. Chemistry of Natural Compounds, 1974, vol. 10, no. 4, p. 551.

6. Varlakov M.N. Izbrannye trudy. [Selected Works]. Moscow, 1963. 172 p. (in Russ.).

7. Sambueva Z.G. Lekarstvennye rasteniia v traditsionnoi i narodnoi meditsine. [Medicinal plants in traditional and folk medicine]. Ulan-Ude, 1987, pp. 127-129. (in Russ.).

8. Tankhaeva L.M., Nikolaeva G.G., Glyzin V.I., Pinchuk I.N. Chemistry of Natural Compounds, 1984, vol. 20, no. 6, p. 747.

9. Tankhaeva L.M., Purev O., Komissarenko N.F., Nikolaeva G.G., Odontuya G. Rastitel'nye Resursy, 1993, vol. 31, pp. 57-61. (in Russ.).

10. Rodriguez S., Wolfender J.-L., Odontuya G., Purev O., Hostettmann K. Phytochemistry, 1995, vol. 40, pp. $1265-1272$.

11. Odontuya G., Kojima K., Rodriguez S., Purev O., Ogihara Y., Hostettmann K. Chemical \& Pharmaceutical Bulletin, 1998, vol. 46, pp. 1827-1828.

12. Purev O., Odontuya G., Khishgee D., Oyun Kh., Tankhaeva L.M., Nikolaeva G.G., Komissarenko N.F. Rastitel'nye Resursy, 1994, vol. 30, pp. 148-151. (in Russ.).

13. Rodriguez S., Wolfender J.-L., Hostettmann K., Odontuya G., Purev O. Helvetica Chimica Acta, 1996, vol. 79, pp. 363-370.

14. Karpovich V.N. Voprosy farmakognozii, 1960, vol. 12, pp. 201-208.

15. Mikhailova T.M., Olennikov D.N., Tankhaeva L.M., Nikolaeva G.G. Chemistry of Natural Compounds, 2005, vol. 41, no. 3, pp. 303-305.

16. Mikhailova T.M., Tankhaeva L.M., Shul'ts E.E., Tolstikov G.A. Chemistry of Natural Compounds, 2005, vol. 41, no. 5, pp. 513-515.

17. Mikhailova T.M., Shul'ts E.E., Tankhaeva L.M., Bodoev N.V., Tolstikov G.A. Khimiya v interesakh ustoychivogo razvitiya, 2005, no. 3, pp. 411-415. (in Russ.).

18. Stout G.H., Christensen E.N., Balkenhol W.J., Stevens K.L. Tetrahedron, 1969, vol. 25, pp. 1961-1973.

19. Stout G.H., Fries J.L. Phytochemistry, 1970, vol. 9, pp. 235-236.

20. Dhasmana H., Garg H.S. Phytochemistry, 1989, vol. 28, pp. 2819-2821.

21. Recio-Iglesias M.-C., Marston A., Hostettmann K. Phytochemistry, 1992, vol. 31, pp. 1387-1389.

22. Stout G.H., Balkenhol W.J. Tetrahedron, 1969, vol. 25, pp. 1947-1960. 
